\title{
DEPENDÊNCIA SETORIAL DE INSUMOS IMPORTADOS DO SETOR AGROPECUÁRIO E DA INDÚSTRIA INTENSIVA EM RECURSOS NATURAIS: UMA ANÁLISE DO PERÍODO DE 1995 A 2009
}

\author{
Valéria Silva Mortari \\ Graduanda do Curso de Ciências Econômicas da Universidade Federal de São Carlos (UFSCar) \\ Endereço para contato: Rua 13 de junho, 1883. Bairro Alto - Aquidauana - MS \\ CEP: 79200-000 - E-mail: valeriasmortari@gmail.com \\ Maria Aparecida Silva Oliveira \\ Professora Associada da Universidade Federal de São Carlos (UFSCar) \\ Endereço para contato: Rodovia João Lemes dos Santos, km 110 - SP-264. Bairro do Itinga - Sorocaba - SP \\ Universidade Federal de São Carlos - Campus de Sorocaba; CCGT - Departamento de Economia. \\ CEP: 18052-780 - E-mail: aparecidaoliveira@ufscar.br
}

Recebido em 04 de março de 2016. Aceito em 12 de julho de 2016.

\section{RESUMO}

Este trabalho tem por objetivo analisar o grau de dependência por insumos importados do setor agropecuário e da indústria intensiva em recursos naturais entre os anos de 1995 e 2009 . Outro ponto é analisar os transbordamentos gerados por tais setores na economia. Desta forma, utilizou-se a análise de insumo-produto, calculando os requerimentos diretos e indiretos por importação de insumos de cada setor e os classificando de acordo com seus respectivos graus de dependência externa. Quanto ao efeito de encadeamento empregaram-se os índices de ligação para frente de Ghosh e o para trás de Rasmussen Hirschman (RH). Foi constatado que a economia apresenta dependência externa de insumos relacionada ao setor agropecuário e que este setor possui importantes encadeamentos a jusante em sua cadeia produtiva. Quanto à indústria intensiva em recursos naturais os resultados podem ser divididos em dois: (1) dois dos quatro setores da indústria extrativa mineral apresentam dependência externa para produzir e dentre os quatro a economia se mostra dependente da importação de três deles como insumos; e (2) a indústria de alimentos mostrou, no geral, baixa dependência externa, e foi no geral classificada como dependente da oferta intersetorialde acordo com seus índices de ligação.

Palavras-chave: dependência; insumos importados; índice de ligação.

\begin{abstract}
This research aims to analyze the degree of dependence on imported inputs in the agricultural sector and natural resources intensive industry among 1995 and 2009. Another point is to analyze the spillovers capacity of these sectors in the economy through their indexes of linkages. To meet the objectives it has been used the input-output analysis, first calculating the direct and indirect requirements for import of each sector inputs and then classifying them according to their degree of external dependence. As for the chaining effect it has been calculated the Ghosh forward linkages indices and Rasmussen Hirschman backwardlinkages indices (RH). It was noted that the economy has dependence on foreign inputs related to the agricultural sector and that this sector has important linkages downstream in the production chain. As fornatural resources intensive industry results can be divided into two: (1) two of the four sectors of the mining industry have direct and indirect
\end{abstract}


requirements for inputs imported above the average for the economy and the economy of the four shown dependent on imports three of them as inputs; and (2) the food industry shows up, in general, whether for import of inputs to produce, except for the processing of plant products sector, which goes from 2000 showing dependence on imported inputs, still, this industry was generally classified as dependent on inter-sectoral supply according to their linkages indices, producing linkages upstream in the supply chain.

Keywords: dependence; imported inputs; linkages indices.

\section{INTRODUÇÃO}

Existe uma discussão recente na literatura científica na qual se evidencia uma mudança estrutural na indústria brasileira que se intensifica a partir das medidas de abertura econômica da década de 1990. Alguns autores como Nassif (2008) e Oreiro e Feijó (2010) mostraram em seus trabalhos que tem ocorrido no Brasil um redirecionamento da produção industrial para a indústria intensiva em recursos naturais. Ainda, discute-se que a atividade econômica tem concentrado suas forças em setores de baixa intensidade tecnológica, como o caso do setor primário.

A indústria intensiva em recursos naturais juntamente com o setor agropecuáriotem historicamente grande relevância para a economia brasileira. Em especial o último setor tem se apresentado como uma alavanca ao comércio externo, auxiliando o país a gerar saldos positivos na balança comercial, ressaltando que a exportação deste setor no ano de 2014 chegou a U\$35.789,9 milhões (IPEADATA). Desta forma, o Brasil desempenha um papel de destaque no cenário internacional no tocante a sua produção no setor agropecuário que atingiu em 2013 o valor de $\mathrm{R} \$ 234.593,6470$ milhões (IPEADATA).

O Brasil não apenas tem se voltado para setores como agropecuária e indústria intensiva em recursos naturais como também vêm ao longo das últimas décadas aumentando sua dependência externa ao elevar gradativamente a parcela de conteúdo importado na produção bens. De acordo com Morceiro, Gomes e Magacho (2012), entre 2003 e 2008 ocorreu uma elevação generalizada do conteúdo importado na produção brasileira de cerca de $60 \%$ que por sua vez reflete-se de forma negativa sobre os elos produtivos, devido à intensificação do processo de substituição de fornecedores internos por estrangeiros.

Kume, Piani e Souza (2003) e Erber (2001) são alguns dos autores que apontaram como motivo do aumento substancial das importações de bens intermediários a abertura comercial e as medidas de desregulamentações impostas na economia brasileira na década de 1990, que juntamente com a sobrevalorização do real resultou no aumento da demanda por importação. Este processo se manteve durante a década de 2000, já que a política macroeconômica brasileira sustentou uma taxa de câmbio valorizada o que segundo Bruno, Araujo e Pimenel (2009) reduziu os custos dos insumos importados e, assim, impulsionou sua maior entrada, enquanto Araújo e Leite (2009) argumentaram que a indústria brasileira tem passado por uma transformação estrutural em decorrência do aumento da parcela de bens intermediários importados na produção devido à política cambial brasileira.

Tendo em vista a relevância do setor agropecuário e da indústria intensiva em recursos naturais juntamente com o processo que a economia brasileira tem passado nas últimas 
décadas, em que a parcela de insumos importados tem se elevado continuamente, pretende-se neste artigo analisar qual o grau de dependência destes setores em relação a insumos importados, quais setores demandam maior quantidade de importação para produzir e de quais setores a economia apresenta maior dependência externa. Sendo que a partir dos resultados gerados será possível expressar de forma quantitativa, quais setores que, quando elevado sua produção aumentam a dependência externa da economia, através de seus requerimentos diretos e indiretos de importação.

Para atender ao objetivo será utilizada como instrumento a análise de insumo-produto, utilizando como base de dados as matrizes de insumo-produto (MIP) dos anos de 1995 a 2009. As matrizes em questão possuem 42 setores dos quais12 serão objetos de análise, ou seja, aqueles que de acordo com a classificação de Pavitti (1984) e OCDE (2005) pertencem à indústria intensiva em recursos naturais (onze) mais o setor de agropecuária. A metodologia utilizada permitirá através da matriz de importação calcular o valor dos requerimentos intersetoriais diretos e indiretos de insumos importados de cada setor. Assim, cada um será classificado de acordo com seu grau de dependência. Serão calculados também os índices de ligação de cada setor o que permitirá analisar a capacidade e direção dos transbordamentos gerados por cada um deles.

Desta forma, o presente trabalho está dividido em 5 seções, incluindo esta introdução. Seguido pela metodologia utilizada, apresentação e discussão de resultados e, por fim, a conclusão obtida do estudo.

\section{METODOLOGIA}

Para atender aos objetivos propostos, ou seja, analisar o grau de dependência de insumos importados da indústria intensiva em recursos naturais e do setor agropecuário, será utilizada a análise de insumo-produto. A seguir estão apresentadas as concepções teóricas desse método de análise, bem como as descrições dos procedimentos para implementá-lo.

\subsection{Matriz de Insumo-Produto (MIP)}

A teoria do insumo-produto foi desenvolvida pelo economista Leontief na década de 1930. Leontief conseguiu retratar a economia em determinado período, captando as relações contemporâneas entre os setores da economia, como se fossem partes de um único organismo. (GUILHOTO, 2004). As relações econômicas assim sintetizadas constituem a matriz de insumo-produto (MIP).

A MIP trata da descrição da economia em termos de circulação, retratando-a como um sistema integrado de fluxos e transferências de insumos e produtos entre setores. Cada um dos setores produz bens e serviços que podem ser utilizados no consumo intermediário por outros setores ou consumidos como demanda final. Por sua vez, esse mesmo setor demanda insumos de outros setores para sua produção. Assim, as vendas realizadas por um setor constituem-se em compras de outros. O segundo setor, percebendo que sua demanda aumentou, comprará mais fatores de outros setores, e assim por diante. Dessa forma, a MIP reflete a complexidade da propagação em cadeia pelo setor produtivo do efeito da decisão de compra ou investimento (MILLER; BLAIR, 2009). 
Essas características fazem com que através da MIP possase detectar as consequências que uma mudança em um setor da economia acarreta para os outros setores, tanto no enfoque macroeconômico quanto no microeconômico. Chiang e Wainwright (2006) afirmaram que a análise de insumo-produto, que tem a MIP como base de dados, é de grande utilidade no planejamento da produção, nos casos do planejamento para o desenvolvimento de um país ou de elaboração de um programa de defesa nacional.

A MIP é composta pela conta de produção global e é dividida em três partes. A primeira retrata a demanda intermediária, isto é, as transações de compra e venda entre os setores produtivos. A segunda é composta pelo valor adicionado, que compreende a remuneração dos fatores e o excedente bruto operacional, os impostos e subsídios incidentes sobre a produção e as importações. A demanda final, a terceira parte da MIP, é composta pelo consumo das famílias e do governo, da formação bruta de capital e das exportações. Uma MIP ilustrativa é apresentada na Figura 1, em que 1 e 2 são setores produtivos, Y é a demanda final, $\mathrm{V}$ é o valor adicionado mais importações e $\mathrm{X}$ representa o total da produção. As variáveis Xij representam o consumo intermediário do insumo i na produção do bem j. Na coluna estão representados os custos com as compras de insumos. Na linha podem ser observadas as receitas do setor oriundas da venda do bem para o consumo intermediário dos demais setores e para a demanda final.

Figura 1 - Matriz Insumo Produto Representativa

\begin{tabular}{|c|c|c|c|c|}
\hline \multirow{2}{*}{$\begin{array}{c}\text { Insumo/Produto } \\
\text { (custos } \downarrow \text { receitas } \rightarrow\end{array}$} & \multicolumn{2}{|c|}{ Setores } & \multirow{2}{*}{$\begin{array}{l}\text { Demanda Final } \\
\text { (Y) }\end{array}$} & \multirow{2}{*}{$\begin{array}{c}\text { Valor Bruto da } \\
\text { Produção ( } \\
\left.X=\sum X_{i j}+Y_{i}\right)\end{array}$} \\
\hline & $\mathrm{X}_{1}$ & $\mathrm{X}_{2}$ & & \\
\hline $\mathrm{X}_{1}$ & $\mathrm{X}_{11}$ & $\mathrm{X}_{12}$ & $\mathrm{Y}_{1}$ & $\mathrm{X}_{1}$ \\
\hline $\mathrm{X}_{2}$ & $\mathrm{X}_{21}$ & $\mathrm{X}_{22}$ & $\mathrm{Y}_{2}$ & $\mathrm{X}_{2}$ \\
\hline Valor Adicionado (V) & $\mathrm{V}_{1}$ & $\mathrm{~V}_{2}$ & & \\
\hline $\begin{array}{l}\text { Valor Bruto da Produção } \\
\qquad\left(\mathrm{X}=\sum \mathrm{X}_{\mathrm{ij}}+\mathrm{V}_{\mathrm{j}}\right)\end{array}$ & $\mathrm{X}_{1}$ & $\mathrm{X}_{2}$ & & \\
\hline
\end{tabular}

Fonte: Elaboração Própria

A partir da matriz de consumo intermediário, pode-se obter a matriz de coeficientes técnicos, que é dada por:

$A=\left[a_{i j}\right]$ em que $a_{i j}=\frac{X_{i j}}{X_{j}}$ ou $X_{i j}=a_{i j} X_{j}$

Para cada linha da MIP, tem-se, então, que:

$$
\sum_{j=1}^{n} X_{i j}+Y_{i}=X_{i}=\sum_{j=1}^{n} a_{i j} X_{j}+Y_{i}
$$

Em termos matriciais, $\mathrm{AX}+\mathrm{Y}=\mathrm{X}$. Com algumas operações matriciais, obtém-se: 


$$
X=(I-A)^{-1} Y \text { ou } X=L Y
$$

em que I é uma matriz identidade e $(I-A)^{-1}=L=[l i j]$ é a matriz inversa de Leontief, em que cada elementolij, segundo Guilhoto (2004), representa os requisitos diretos e indiretos de insumos do setor i por unidade de demanda final na produção do setor j. A equação (3) descreve o modelo básico de Leontief.

\subsection{Grau de dependência de insumos importados}

Para a análise da dependência de insumos importados será utilizado o método proposta por Schuschny (2005). Tal método consiste inicialmente em calcular os requerimentos diretos de insumo importado setorial. Seja $A^{m}$ a matriz de coeficientes técnicos importados dada por:

$$
A^{m}=\left[a_{i j}^{m}\right] \text { em que } a_{i j}^{m}=\frac{X_{i j}}{X_{j}}
$$

Sendo $X_{i j}^{m}$ o valor dos insumos i importado pelo setor $\mathrm{j}$ e $a i \mathrm{j}^{\mathrm{m}} \mathrm{o}$ coeficiente que mede o valor da importação do insumo i pelo setor j para cada unidade monetária produzida por este setor. Assim, obtém-se a matriz de importações totais através da pós-multiplicação da matriz de coeficientes de importação pela inversa de Leontief, como a seguir:

$$
Q=A^{m} \operatorname{Lou} Q=[q i j]
$$

Cada elemento qij indica as importações direta e indiretas do insumo i necessárias para gerar uma unidade monetária da produção do setor $\mathrm{j}$. A soma da coluna $\mathrm{j}$ da matriz $Q\left(Q_{j}=\right.$ $\sum_{i=1}^{n} q_{i j}$ ) informa o conteúdo total de importações necessário para produzir domesticamente uma unidade monetária do setor j. Segundo Schuschny (2005), esse cálculo apresenta uma informação estrutural sumamente útil pois permite identificar as atividades cuja dependência do resto do mundo seja relevante em termos de demanda de importação, ou seja, que dependem do exterior para incrementar seu nível de produção. Por sua vez, a soma da linha i da matriz $Q\left(Q_{i}=\sum_{j=1}^{n} q_{i j}\right)$ indica a importação do insumo i necessária caso a demanda final de todos os setores se eleve em uma unidade monetária. Esse indicador permite conhecer os setores dos quais a economia tem maior dependência do exterior, isto é, aqueles mais presentes no fluxo de importações quando há uma expansão da produção doméstica.

Comparando os indicadores acima descritos com a suas médias chega-se a uma classificação setorial que agrupa os setores de acordo com o seu comportamento de demandante ou demandado de insumos intermediários provenientes do exterior, como apresentado na Figura 2 abaixo.

Figura 2 - Classificação setorial segundo requerimentos de importações de insumos. 


\begin{tabular}{|c|c|c|}
\hline & $\begin{array}{c}\text { Demandantes } \\
\left(Q_{j}>\sum_{j=1}^{n} Q_{j} / n\right)\end{array}$ & $\begin{array}{c}\text { Pouco demandantes } \\
\left(Q_{j} \leq \sum_{j=1}^{n} Q_{j} / n\right)\end{array}$ \\
\hline $\begin{array}{c}\text { Demandados } \\
\left(Q_{i}>\sum_{i=1}^{n} Q_{i} / n\right)\end{array}$ & Tipo II & Tipo I \\
\hline $\begin{array}{c}\text { Pouco demandados } \\
\left(Q_{i} \leq \sum_{i=1}^{n} Q_{i} / n\right)\end{array}$ & Tipo III & Tipo IV \\
\hline
\end{tabular}

Fonte: Adaptado de Schuschny (2005)

Assim, os setores classificados como demandantes são aqueles que apresentam requerimentos diretos e indiretos de insumos importados acima da média da economia, e os classificados como demandados são os que quando a produção da economia se expande a sua demanda, direta e indireta, se eleve acima da média de importação de insumos.

\section{3 Índices de Ligação}

Tomando como ponto de partida o modelo básico de Leontief e tendo em vista Rasmussem (1956) e Hirschman (1958)é possível calcular os Índices de Ligação para Trás(ILT)que permitem analisar o poder de encadeamento dos setores em sua cadeia produtiva (GUILHOTO,2004). Desta forma, a partir dos elementos da matriz inversa de Leontief definidos como $1_{\mathrm{ij}}$ tem-se:

$$
I L T_{j}=\frac{1 / n \sum_{i=1}^{n} l_{i j}}{1 / n^{2} \sum_{i=1}^{n} \sum_{j=1}^{n} l_{i j}}
$$

Quanto ao Índice de Ligação para Frente (ILF)será empregado a metodologia de Ghosh a qual demonstra a importância de cada setor como fornecedor de insumos ao restante da economia. Considerando a matriz K:

$$
K=(\widehat{X})^{-1} Z
$$

Sendo cada elemento da matriz K:

$$
K_{i j}=\frac{z_{i j}}{x_{i}}
$$

Pode-se definir a matriz $\mathrm{G}$ como:

$$
G=(I-K)^{-1}
$$

Assim, pelos elementos da matriz G chega-se ao índice de ligação para frente de Ghosh:

$$
I L F_{i}=\frac{1 / n \sum_{j=1}^{n} g_{i j}}{1 / n^{2} \sum_{i=1}^{n} \sum_{j=1}^{n} g_{i j}}
$$


Figura 3 - Classificação setorial segundo os índices de ligações para trás e para frente ${ }^{1}$

\begin{tabular}{|c|c|c|}
\hline Índices de ligação & ILT $>1$ & ILT $<1$ \\
\hline ILF $>1$ & Setor Chave & Dependente da demanda intersetorial \\
\hline ILF $<1$ & Dependente da oferta intersetorial & Independente \\
\hline
\end{tabular}

Fonte: Adaptado de Miller e Blair (2009).

\subsection{Fonte dos dados}

Serão utilizadas as matrizes de insumo-produto dos anos 1995 a 2009 estimadas, com base nos dados do Sistema de Contas Nacionais(SCN) do IBGE (Instituto Brasileiro de Geografia e Estatística), por Guilhoto e Sesso Filho (2005 e 2010), disponibilizados no site do NEREUS. As matrizes de insumo-produto e de importação de insumos intermediários estão desagregadas em 42 setores e 80 produtos, permitindo a análise detalhada da dependência externa da produção nacional.

Os dados contidos nas matrizes estão medidos em mil reais a preços do ano corrente, não sendo necessário, portanto, a conversão de valores dos insumos importados.

Para a melhor compreensão dos resultados utiliza-se a classificação de Pavitti (1984) e OCDE (2005) agrupando os setores de acordo com o seu tipo de indústria, como foi destacado na introdução deste trabalho. Assim, os setores estão reunidos em grupos que possuem características industriais semelhantes, de modo que, a discussão está subdividida da seguinte forma: indústria intensiva em recursos naturais e o setor agropecuário.

\section{RESULTADOS E DISCUSSÃO}

\subsection{Indústria Intensiva em Recursos Naturais}

Os setores que pertencem à indústria intensiva em recursos naturais são: refino do petróleo, indústria do café, beneficiamento de produtos vegetais, abate de animais, indústria de laticínios, fabricação de açúcar, fabricação de óleos vegetais, outros produtos alimentícios, extrativa mineral, petróleo e gás e mineral não metálico. Esses setores estão dispostos no Quadro 1, onde podem ser observadas suas classificações de acordo com seus requerimentos direto e indireto por insumos importados e índices de ligação respectivamente, durante o período estudado.

O setor de refino de petróleo é classificado como setor chave na economia devida sua capacidade de gerar transbordamentos aos setores localizados a montante e a jusante em sua cadeia produtiva. Sendo válido ressaltar que os ILT e ILF deste setor apresentaram uma média de 1,15 e 2,28 respectivamente no período de 1995 a 2009, ou seja, ambos superiores a unidade. Esse setor foi qualificado, de acordo com seus requerimentos diretos e indiretos de insumos importados, como Tipo II. O que significa que este setor apresenta requerimentos por

\footnotetext{
${ }^{1}$ A classificação setorial segundo os índices de ligação para trás e para frente foram feitos à partir dos valores encontrados pelo cálculo apresentado na metodologia. Estes valores estão apresentados no Apêndice 1 deste artigo.
} 
importação de bens intermediários acima da média da economia e também é um insumo do qual a economia, para aumentar a produção, depende da importação.

Ao analisar o setor de refino de petróleo separadamente na matriz Q, na qual cada elemento $\mathrm{q}_{\mathrm{ij}}$ representa as importações diretas e indiretas de insumos do setor i para produzir uma unidade monetária do setor j, observa-se que durante todo período de 1995 a 2009 o principal insumo importado provém do setor de petróleo e gás, representando em média 55\% do total de suas importações. Desta forma, constata-se que o setor de refino de petróleo apresenta dependência de um insumo que está estritamente relacionado ao seu produto final.

Gráfico 1 - Valor do Requerimento Direto e Indireto de Insumos Importados da Indústria Extrativa Mineral e Refino de Petróleo de 1995 a 2009 (em reais)

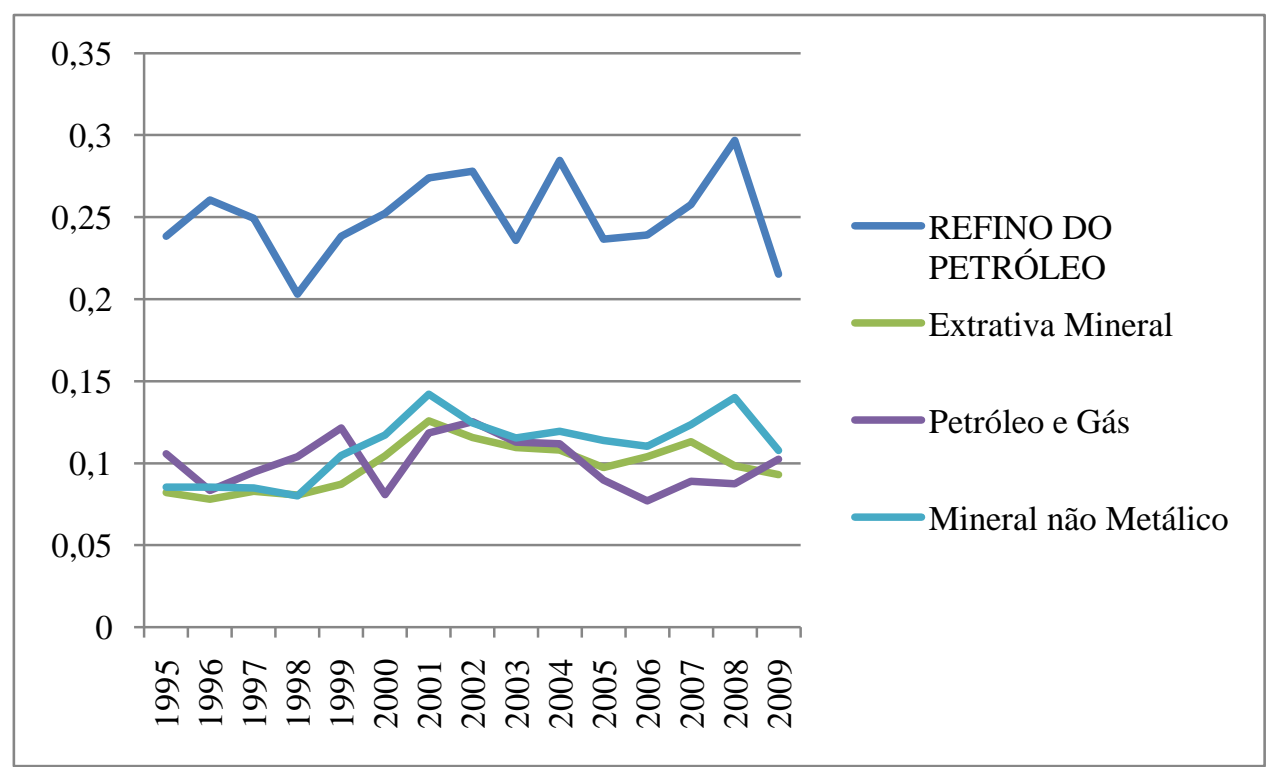

Fonte: Elaboração própria a partir das MIPs estimadas pelo NEREUS com base no SCN (IBGE, 2009).

Pelo Gráfico 1 nota-se que dentre os setores que compõem a indústria extrativa mineral o setor de refino de petróleo é o que possui maior requerimento de importação.De fato, esse setor importa direta e indiretamente em média do período estudado, cerca de $\mathrm{R} \$ 0,25$ para cada real produzido, alcançando em 2008 o valor de $\mathrm{R} \$ 0,29$. Da mesma forma, pelo Gráfico3, verifica-se que quando a produção dos demais setores da economia se expande em um real a demanda direta e indireta por importação ligada a este setor é de acordo com a média do período analisado de $\mathrm{R} \$ 0,93$. Este valor alcança, em $2001, \mathrm{R} \$ 1,18$ de importação direta e indireta de insumos sendo $\mathrm{R} \$ 0,68$ apenas a demanda direta.

Ao fazer uma média de todos os setores para o período estudado observa-se que aqueles que apresentam maior dependência por importação de insumos de refino de petróleo são: mineral não metálico; madeira e mobiliário; celulose, papel e gráfica; indústria da borracha; refino do petróleo; químicos diversos; farmácia e veterinária; artigos plásticos; indústria têxtil; fabricação de calçados; indústrias diversas; e transportes. Os setores citados foram aqueles que apresentaram uma média por importação de refino de petróleo acima de $20 \%$ do total de insumos importados por cada setor, tendo ênfase os setores da indústria da borracha (44\%), químicos diversos (37\%) e artigos plásticos (49,8\%). 
Quadro 1 - Classificação do Grau de Dependência de Insumos Importados e índice de Ligação da Indústria Intensiva em Recursos Naturais de 1995 a 2009

\begin{tabular}{|c|c|c|c|c|c|c|c|c|c|c|c|c|c|c|c|}
\hline Setores & 95 & 96 & 97 & 98 & 99 & 00 & 01 & 02 & 03 & 04 & 05 & 06 & 07 & 08 & 09 \\
\hline \multirow{2}{*}{$\begin{array}{l}\text { Refino Do } \\
\text { Petróleo }\end{array}$} & T. II & T. II & T. II & T. II & T. II & T. II & T. II & T. II & T. II & T. II & T. II & T. II & T. II & T. II & T. II \\
\hline & S. Chave & $\begin{array}{c}\text { S. } \\
\text { Chave }\end{array}$ & $\begin{array}{c}\text { S. } \\
\text { Chave }\end{array}$ & $\begin{array}{c}\text { S. } \\
\text { Chave }\end{array}$ & $\begin{array}{c}\text { S. } \\
\text { Chave }\end{array}$ & $\begin{array}{c}\text { S. } \\
\text { Chave }\end{array}$ & $\begin{array}{c}\text { S. } \\
\text { Chave }\end{array}$ & $\begin{array}{c}\text { S. } \\
\text { Chave }\end{array}$ & $\begin{array}{c}\text { S. } \\
\text { Chave }\end{array}$ & $\begin{array}{c}\text { S. } \\
\text { Chave }\end{array}$ & $\begin{array}{c}\text { S. } \\
\text { Chave }\end{array}$ & $\begin{array}{c}\text { S. } \\
\text { Chave }\end{array}$ & $\begin{array}{c}\text { S. } \\
\text { Chave }\end{array}$ & $\begin{array}{c}\text { S. } \\
\text { Chave }\end{array}$ & $\begin{array}{c}\text { S. } \\
\text { Chave }\end{array}$ \\
\hline \multirow{2}{*}{$\begin{array}{c}\text { Indústria Do } \\
\text { Café }\end{array}$} & T. IV & T. IV & T. IV & T. IV & T. IV & T. IV & T. IV & T. IV & T. IV & T. IV & T. IV & T. IV & T. IV & T. IV & T. IV \\
\hline & DOI & DOI & DOI & DOI & DOI & DOI & DOI & DOI & DOI & DOI & DOI & DOI & DOI & DOI & DOI \\
\hline \multirow{2}{*}{$\begin{array}{l}\text { Benef. Prod. } \\
\text { Vegetais }\end{array}$} & T. IV & T. IV & T. IV & T. IV & T. IV & T. III & T. III & T. III & T. III & T. III & T. III & T. III & T. III & T. III & T. III \\
\hline & DOI & DOI & DOI & DOI & DOI & DOI & DOI & DOI & DOI & DOI & DOI & DOI & DOI & DOI & DOI \\
\hline \multirow{2}{*}{$\begin{array}{l}\text { Abate De } \\
\text { Animais }\end{array}$} & T. IV & T. IV & T. IV & T. IV & T. IV & T. IV & T. IV & T. IV & T. IV & T. IV & T. IV & T. IV & T. IV & T. IV & T. IV \\
\hline & DOI & DOI & DOI & DOI & DOI & DOI & DOI & DOI & DOI & DOI & DOI & DOI & DOI & DOI & DOI \\
\hline \multirow{2}{*}{$\begin{array}{l}\text { Indústria De } \\
\text { Laticínios }\end{array}$} & T. IV & T. IV & T. IV & T. IV & T. IV & T. IV & T. IV & T. IV & T. IV & T. IV & T. IV & T. IV & T. IV & T. IV & T. IV \\
\hline & DOI & DOI & DOI & DOI & DOI & DOI & DOI & DOI & DOI & DOI & DOI & DOI & DOI & DOI & DOI \\
\hline \multirow{2}{*}{$\begin{array}{l}\text { Fabricação } \\
\text { De Açúcar }\end{array}$} & T. IV & T. IV & T. IV & T. IV & T. IV & T. IV & T. IV & T. IV & T. IV & T. IV & T. IV & T. IV & T. IV & T. IV & T. IV \\
\hline & DOI & DOI & DOI & DOI & DOI & DOI & DOI & DOI & DOI & DOI & DOI & DOI & DOI & DOI & DOI \\
\hline \multirow{2}{*}{$\begin{array}{c}\text { Fab. Óleos } \\
\text { Vegetais }\end{array}$} & T. IV & T. IV & T. III & T. IV & T. IV & T. IV & T. IV & T. IV & T. IV & T. IV & T. IV & T. IV & T. IV & T. IV & T. IV \\
\hline & DOI & DOI & DOI & DOI & DOI & DOI & DOI & DOI & DOI & DOI & DOI & DOI & DOI & DOI & DOI \\
\hline \multirow{2}{*}{$\begin{array}{c}\text { Outros Prod. } \\
\text { Aliment. } \\
\text {. }\end{array}$} & T. III & T. III & T. III & T. III & T. III & T. IV & T. IV & T. IV & T. III & T. IV & T. IV & T. IV & T. IV & T. IV & T. IV \\
\hline & DOI & DOI & DOI & DOI & DOI & DOI & DOI & DOI & DOI & DOI & DOI & DOI & DOI & DOI & DOI \\
\hline \multirow{2}{*}{$\begin{array}{l}\text { Extrativa } \\
\text { Mineral }\end{array}$} & T. IV & T. IV & T. IV & T. IV & T. IV & Tipo I & Tipo I & Tipo I & Tipo I & Tipo I & Tipo I & Tipo I & T. II & Tipo I & Tipo I \\
\hline & DDI & ind. & ind. & ind. & ind. & ind. & ind. & ind. & ind. & ind. & ind. & ind. & DOI & ind. & ind. \\
\hline \multirow{2}{*}{$\begin{array}{c}\text { Petróleo E } \\
\text { Gás } \\
\end{array}$} & T. II & Tipo I & T. II & T. II & T. II & Tipo I & Tipo I & T. II & Tipo I & Tipo I & Tipo I & Tipo I & Tipo I & Tipo I & Tipo I \\
\hline & S. Chave & DOI & DOI & DOI & DOI & DDI & DDI & DDI & DDI & DDI & DDI & DDI & DDI & DDI & DDI \\
\hline \multirow{2}{*}{$\begin{array}{c}\text { Mineral Não } \\
\text { Metálico }\end{array}$} & T. IV & T. IV & T. IV & T. IV & T. IV & T. III & T. III & T. III & T. IV & T. III & T. III & T. III & T. III & T. III & T. III \\
\hline & DDI & DOI & ind. & ind. & DOI & ind. & ind. & ind. & ind. & ind. & ind. & ind. & DOI & DOI & ind. \\
\hline
\end{tabular}

Fonte: Elaboração própria a partir das MIPs estimadas pelo NEREUS com base no SCN (IBGE, 2009).

DOI: dependente da oferta intersetorial; DDI: dependente da demanda intersetorial; ind.: independente 
De acordo com os índices de ligação a indústria do café foi classificada como dependente da oferta intersetorial, como mostra o Quadro 1, estabelecendo elos relevantes a montante em sua cadeia produtiva, de tal forma que os valores dos índices de ligação para trás deste setor foram maiores que 1 e apresentaram um valor médio durante o período estudado de 1,23. Deste modo pode-se dizer que ao expandir sua produção os setores que lhes ofertam insumos são conjuntamente estimulados, sendo esses estímulos superiores à média nacional. A indústria do café apresentou requerimento direto e indireto de insumos importados abaixo da média da economia e da mesma forma a economia mostrou-se pouco dependente da importação de insumos ligados a este setor, sendo desta forma classificado como T. IV. O baixo grau de dependência de importação de insumos da indústria de café condiz com o histórico do país neste setor, que possui representatividade em termos de produção e exportação tendo, portanto, uma cadeia estabelecida internamente capaz de atender sua demanda.

O setor de beneficiamento de produtos vegetais foi classificado durante o período como dependente da oferta intersetorial tendo, portanto, alta capacidade transbordamento para trás em sua cadeia produtiva, desta maneira o setor foi considerado como um demandante importanteao apresentar durante todo o período valores do ILT acima de 1 e com um valor médio de 1,14. Quanto ao grau de dependência de insumos importados este setor deixa de ser considerado como T. IV passando em 2000 a ser classificado como T. III, ou seja, o setor até 1999 apresentava requerimentos diretos e indiretos de insumos importados abaixo da média da economia e a demanda por importação de insumos ligado a este setor era menor que a média da economia. A partir de 2000, o setor se mantém pouco demandado pela economia, porém passa a ser considerado como demandante de insumos importados. Como pode ser verificado no Gráfico 2, a partir de 1999, ano da mudança de regime de câmbio fixo para flexível, o setor experimentou uma mudança relevante no valor médio da sua dependência direta e indireta de insumos importados. Ainda, no Gráfico 4, percebe-se que ano mesmo ano a dependência da economia em relação a insumos importados desse setor apresentou um crescimento expressivo. 
Gráfico 2 - Valor do Requerimento Direto e Indireto por Insumos Importados da Indústria de Alimentosde 1995 a 2009 (em reais)

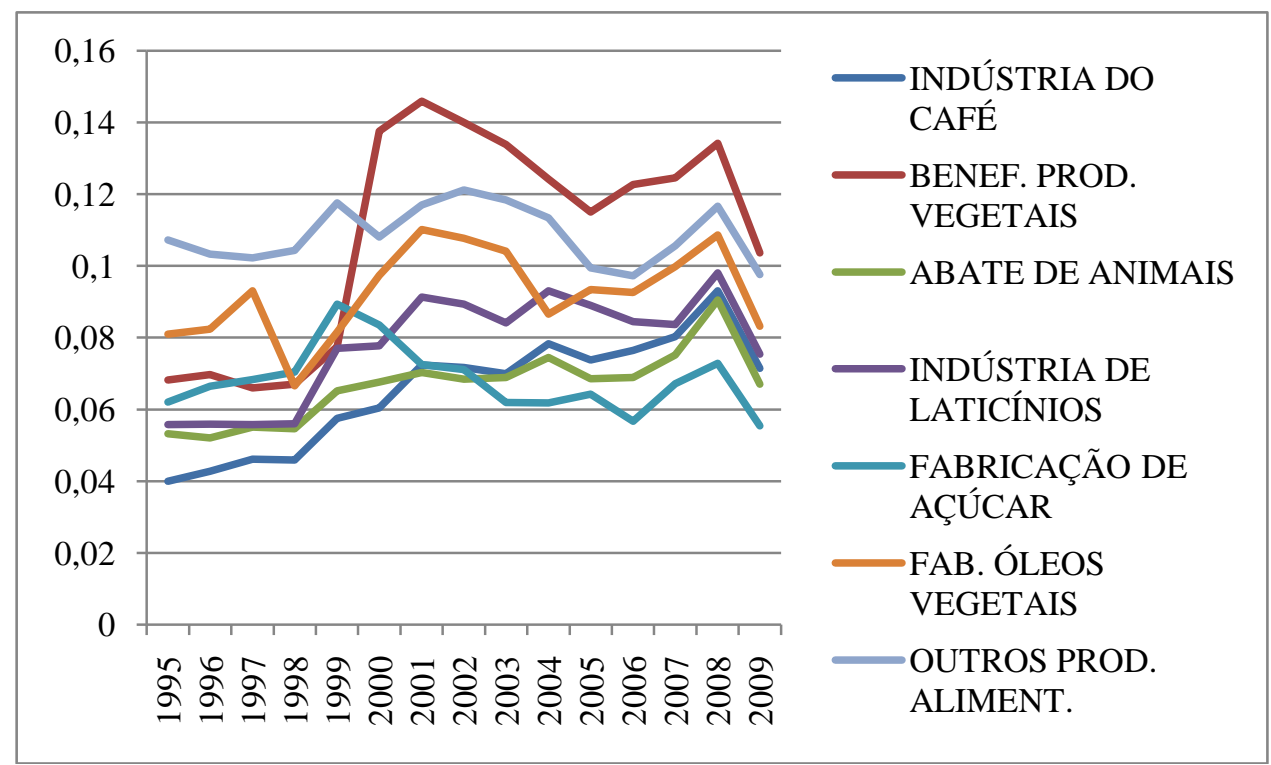

Fonte: Elaboração própria a partir das MIPs estimadas pelo NEREUS com base no SCN (IBGE, 2009).

Ao analisar o setor de beneficiamento de produtos vegetais na matriz de requerimentos diretos e indiretos observa-se que o insumo importado pelo qual apresenta maior dependência está ligado ao setor de agropecuária. Entre 1995 e 1999, este setor importava em média $\mathrm{R} \$ 0,07$ para cada real produzido, no entanto este valor a partir de 2000 quase duplica passando a ser em média $\mathrm{R} \$ 0,12$. A economia, contudo apresenta durante todo o período analisado uma média de importação ligada a este setor de $\mathrm{R} \$ 0,02$ por cada real produzido nos demais setores, ou seja, apresenta baixa dependência externa por beneficiamento de produtos vegetais, embora crescente.

Os setores de abate de animais, indústria de laticínios, fabricação de açúcar e fabricação de óleos vegetais apresentam características semelhantes quanto suas classificações. Estes setores são classificados como Tipo IV quanto ao grau de dependência externa por insumos e são também considerados como dependentes da oferta intersetorial de acordo com seus respectivos índices de ligação, apresentando, portanto valores maiores que a unidade em seus respectivos ILT, os quais estão detalhados no Apêndice 1. É comum para estes setores demandarem insumos primários para serem processados e então chegar-se ao produto final, sendo o Brasil um dos principais produtores mundiais de tais insumos, os setores supracitados apresentam baixa dependência externa. 
Gráfico 3 - Valor do Requerimento Direto e Indireto da Economia por Insumos Importados da Indústria Extrativa Mineral e Refino de Petróleo de 1995 a 2009 (em reais)

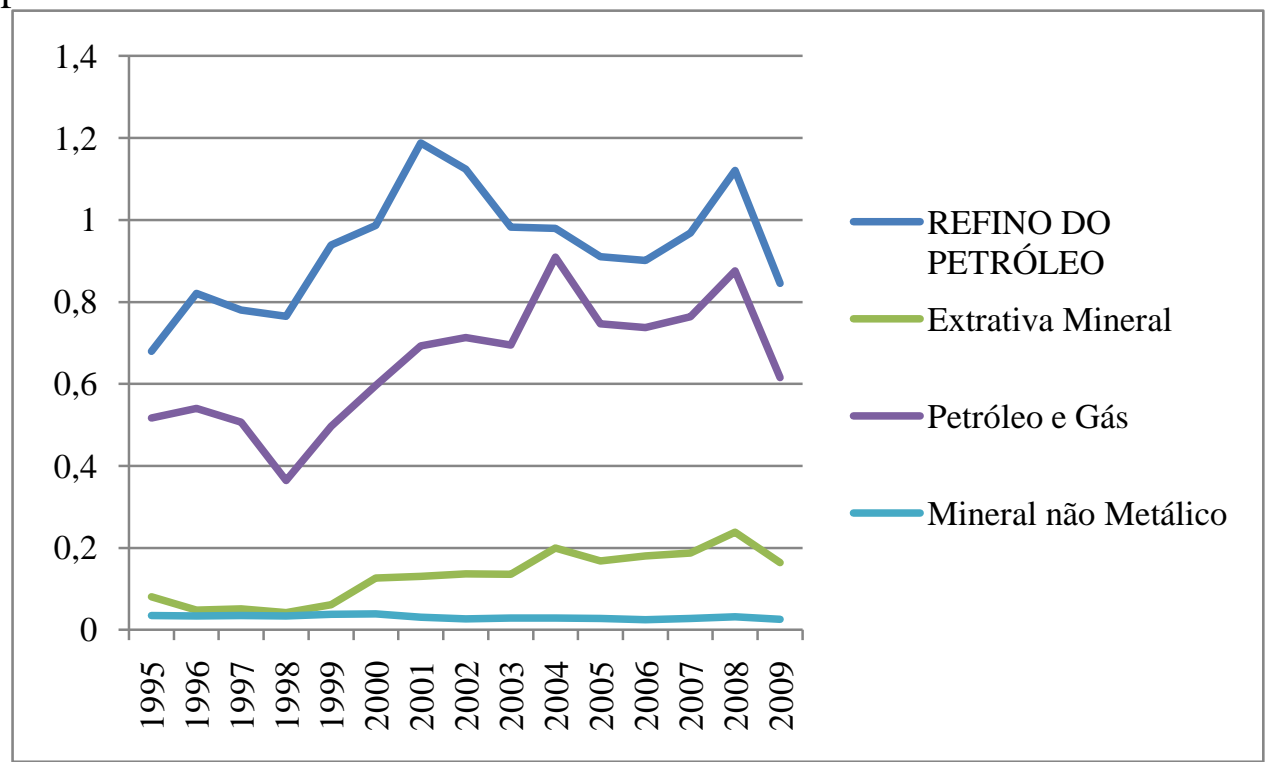

Fonte: Elaboração própria a partir das MIPs estimadas pelo NEREUS com base no SCN (IBGE, 2009).

O setor de outros produtos alimentares foi classificado como dependente da oferta intersetorial, de acordo com seus índices de ligação sendo, portanto, um demandante importante na economia. Esta classificação se deve ao fato de os ILT deste setor apresentarem, durante todo o período, valores acima de 1. Quanto ao seu grau de dependência externa, este setor sofre algumas variações durante o período analisado, de Tipo III para Tipo IV. Quando considerado como Tipo III, ou seja, como demandante de insumos importados, sua principal dependência estava vinculada ao setor de agropecuária, porém a demanda por importação deste insumo decresce ao longo do tempo, de forma que o setor de outros produtos alimentares passa a ser classificado como Tipo IV tornando-se além de pouco demandado também pouco demandante de insumos importados. Desta forma, pode-se inferir que este setor substituiu fornecedores externos por nacionais o que reforça a sua característica de importante demandante.

O setor extrativo mineral sofreu alterações em suas classificações tanto no que diz respeito ao seu grau de dependência externa quanto aos índices de ligação. Do ano de 1995 a 1999, este setor foi classificado como Tipo IV (pouco demandado e pouco demandante de insumos importados) a partir de 2000 passa a ser considerado como tipo I com exceção do ano 2007 em que se qualifica como Tipo II, como pode ser visto pelo Quadro 1. É interessante notar que ser considerado como Tipo I significa que quando ocorre uma expansão na produção nacional a demanda por importação ligada a este setor se eleva acima da média da economia.

Ao analisar separadamente o setor de extrativa mineral na matriz de requerimento direto e indireto de insumos importados observa-se que os setores da economia que apresentam maior dependência externa deste insumo são: metalurgia de não ferrosos, elementos químicos e mineral não metálico. Outrossim, quando estimulada a produção dos demais setores da economia em um real, tem-se em contrapartida uma elevação na demanda direta e indireta, em média do período estudado, de $\mathrm{R} \$ 0,13$ de importação do setor de extrativa mineral, como pode ser visto pelo Gráfico 3. Este setor foi ainda no geral considerado como independente de 
acordo com seus índices de ligação, ou seja, possui reduzido poder de encadeamentos tanto a montante quanto a jusante na cadeia produtiva.

Gráfico 4 - Valor do Requerimento Direto e Indireto da Economia por Insumos Importados da Indústria de Alimentos de 1995 a 2009 (em reais)

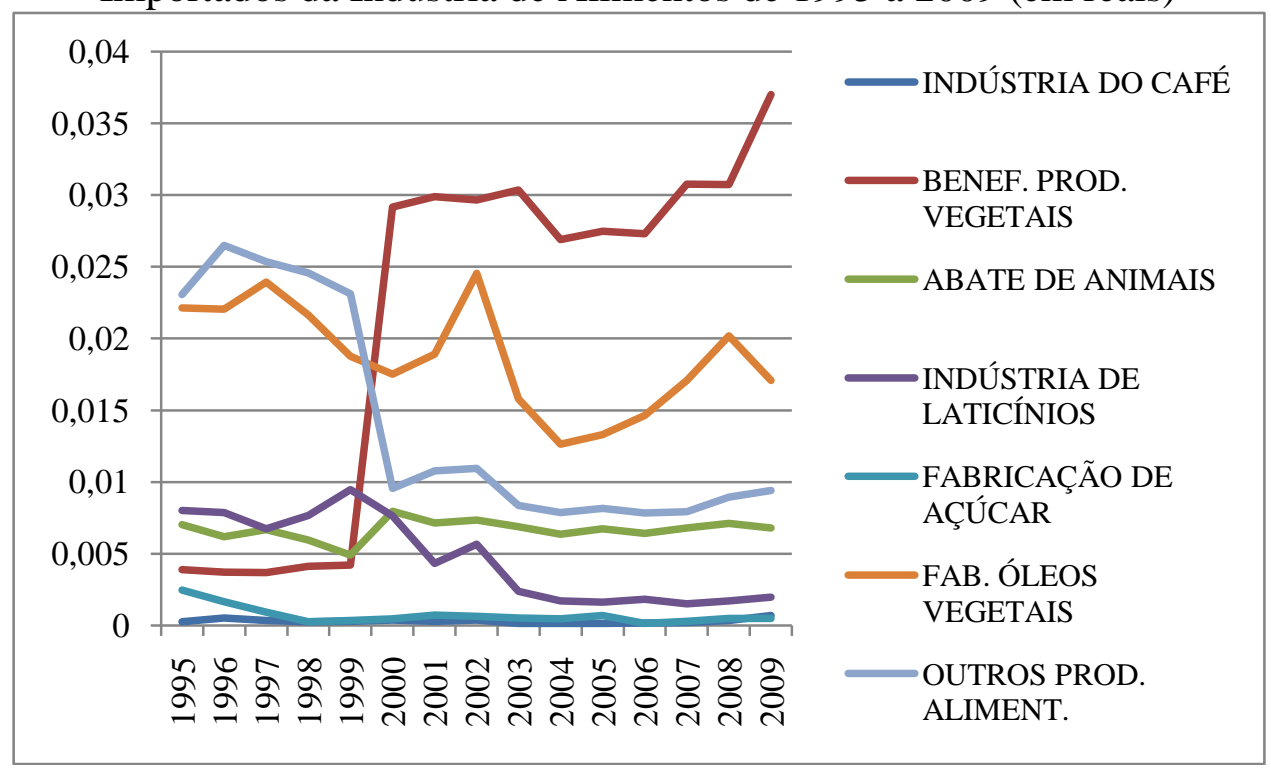

Fonte: Elaboração própria a partir das MIPs estimadas pelo NEREUS com base no SCN (IBGE, 2009).

O setor de petróleo e gás oscila entre Tipo II e tipo I quanto à sua classificação de dependência externa. Quando considerado como Tipo II, ou seja, como um setor demandado e demandante de insumos importados, significa que o setor de petróleo e gás apresenta dependência externa para produzir e a economia demanda importação acima da média ligada a este setor. Quando, porém qualificado como Tipo I, quer-se dizer que o setor apresenta fraca demanda por importações, enquanto os demais setores mostram dependência acima da média da economia por importação de insumos deste setor, ou seja, é considerado demandado e pouco demandante de importações.

A partir da matriz de requerimentos diretos e indiretos de importações observa-se que, dado o setor de petróleo e gás ser demandado acima da média como importação pela economia, os principais setores que apresentam dependência externa por tal insumo são: siderurgia, indústria da borracha, refino do petróleo, artigos plásticos e químicos diversos (a partir do ano 2000). É interessante notar que estes mesmos setores apresentam dependência por importação do setor de refino de petróleo o qual se mostra o principal demandante de petróleo e gás oriundo de fornecedores externos.

A mudança de classificação para tipo I pode significar que o setor de petróleo e gás substituiu fornecedores de insumo externos por nacionais em sua produção. No entanto, ainda não é capaz de suprir a demanda necessária à economia, portanto ainda é considerado um insumo demandado pelos demais setores. No que diz respeito ao índice de ligação tem-se que este setor no geral é classificado como dependente da demanda intersetorial, ou seja, é considerado um fornecedor importante tendo impactos significativos a jusante em sua cadeia produtiva. Ser considerado como um setor dependente da demanda intersetorial significa que os seus ILF apresentaram valores acima de 1, no entanto, entre 1996 e 1999 os valores deste índice foi abaixo de 1 , de forma que, os encadeamentos à jusante gerados pelo setor de 
petróleo e gás durante estes anos foram considerados abaixo da média de encadeamentos gerados pela economia. Porém, mesmo que durante alguns anos o ILF tenha assumido valores inferiores a um, a média entre 1995 e 2009 dos valores dos ILF deste setor foi de 1,24.

O setor de mineral não metálico também não apresenta uniformidade em sua classificação sendo considerado inicialmente como Tipo IV e posteriormente como Tipo III. Essa mudança pode significar que o setor de mineral não metálico substituiu durante o período analisado fornecedores internos por externos, já que inicialmente era qualificado como pouco demandado e pouco demandante e passa a ser demandante de insumos importados. Pela matriz de requerimentos diretos e indiretos de insumos importados vê-se que a partir de 2000 este setor passa a demandar importação de insumos acima da média da economia, principalmente ligado aos setores: extrativa mineral, petróleo e gás e refino de petróleo.

A dependência externa da economia pelo setor de mineral não metálico permanece, no entanto, durante o período estudado abaixo da média sendo, portanto um insumo importado pouco demandado pelos demais setores como o Gráfico 3 expõe. Quanto aos seus índices de ligação também ocorrem variações, sendo considerado em alguns anos como setor independente, de forma que possui baixos índices de ligação com os setores pertencentes a sua cadeia produtiva, e como dependente da oferta intersetorial sendo assim considerado como um relevante consumidor de forma que um aumento em sua produção tem impacto sobre aqueles que estão à montante de sua cadeia produtiva.Ressalta-se que os valores assumidos pelos índices de ligação deste setor estão expostos no Apêndice 1.

É possível, através dos resultados obtidos, dizer que a indústria de alimentos no geral é classificada como dependente da oferta intersetorial, de forma que são importantes consumidores na economia, gerando transbordamentos para trás em suas cadeias produtivas. Outra observação é que cinco dos sete setores desta indústria, que representam 48,6\% do seu valor adicionado em 2009, foram classificados como Tipo IV de acordo com seus requerimentos diretos e indiretos de insumo, ou seja, são setores que não apresentam dependência externa e dos quais a economia apresente também baixa dependência para produzir.

No entanto, o setor de beneficiamento de produtos vegetais apresenta uma mudança em sua classificação passando a ser do Tipo III, ou seja, ele passa a ser considerado um setor demandante, o qual para produzir demanda insumos importados acima da média da economia, sendo que esta mudança significa que o setor substituiu durante o período estudado fornecedores internos por estrangeiros ou, ainda, que a mudança do regime cambial em 1999, e a consequente depreciação do real, elevou os custos com insumos importados para o setor que não foi capaz de substituí-los. Com o setor de outros produtos alimentícios ocorre o oposto, ou seja, deixa de ser considerado como Tipo III e passa a ser Tipo. IV que por sua vez significa que este setor substitui fornecedores estrangeiros por internos.

Em relação à indústria extrativa, a economia brasileira mostra dependência externa por três dos quatro setores que a compõem, os quais representam $82,31 \%$ do seu valor adicionado em 2009, de forma que para elevar sua produção aumenta concomitantemente sua demanda direta e indireta de insumos importados dos setores: refino de petróleo; extrativa mineral; e petróleo e gás. Já os setores de refino de petróleo e mineral não metálico são setores que para produzirem apresentam requerimentos diretos e indiretos por insumos importados acima da média da economia. 


\subsection{Agropecuária}

Ao analisar o setor brasileiro de agropecuária vê-se que este foi classificado, de acordo com seus índices de ligação, como dependente da demanda intersetorial, ou seja, é considerado um fornecedor importante na economia, gerando transbordamentos a jusante em sua cadeia produtiva, como pode ser observado pelo Quadro 2.

Quadro 2 - Classificações do Setor Agropecuário de 1995 a 2009

\begin{tabular}{|c|c|c|c|c|c|c|c|c|c|c|c|c|c|c|c|}
\hline Setor & $\mathbf{9 5}$ & $\mathbf{9 6}$ & $\mathbf{9 7}$ & $\mathbf{9 8}$ & $\mathbf{9 9}$ & $\mathbf{0 0}$ & $\mathbf{0 1}$ & $\mathbf{0 2}$ & $\mathbf{0 3}$ & $\mathbf{0 4}$ & $\mathbf{0 5}$ & $\mathbf{0 6}$ & $\mathbf{0 7}$ & $\mathbf{0 8}$ & $\mathbf{0 9}$ \\
\hline Agrope & Tipo & Tip & Tip & Tip & Tip & Tip & Tip & Tip & Tip & Tip & Tip & Tip & Tip & Tip & Tip \\
cuária & I & o I & o I & o I & o I & o I & o I & o I & o I & o I & o I & o I & o I & o I & o I \\
\cline { 2 - 11 } & DDI & DD & DD & DD & DD & DD & DD & DD & DD & DD & DD & DD & DD & DD & DD \\
& & I & I & I & I & I & I & I & I & I & I & I & I & I & I \\
\hline
\end{tabular}

Fonte: Elaboração própria a partir das MIPs estimadas pelo NEREUS com base no SCN (IBGE, 2009).

Quanto o grau de dependência por insumos importados o setor de agropecuária foi considerado como tipo I, o que por sua vez significa que a economia apresenta requerimentos diretos e indiretos de bens intermediários à produção ligados a este setor acima da média da economia, de forma que é considerado um setor demandado. No entanto, esta classificação também demonstra que o setor de agropecuária apresenta baixa dependência externa por insumos sendo, portanto um setor pouco demandante.

Gráfico 5 - Valor do Requerimento Direto e Indireto do Setor de Agropecuária por Insumos Importados de 1995 a 2009 (em reais)

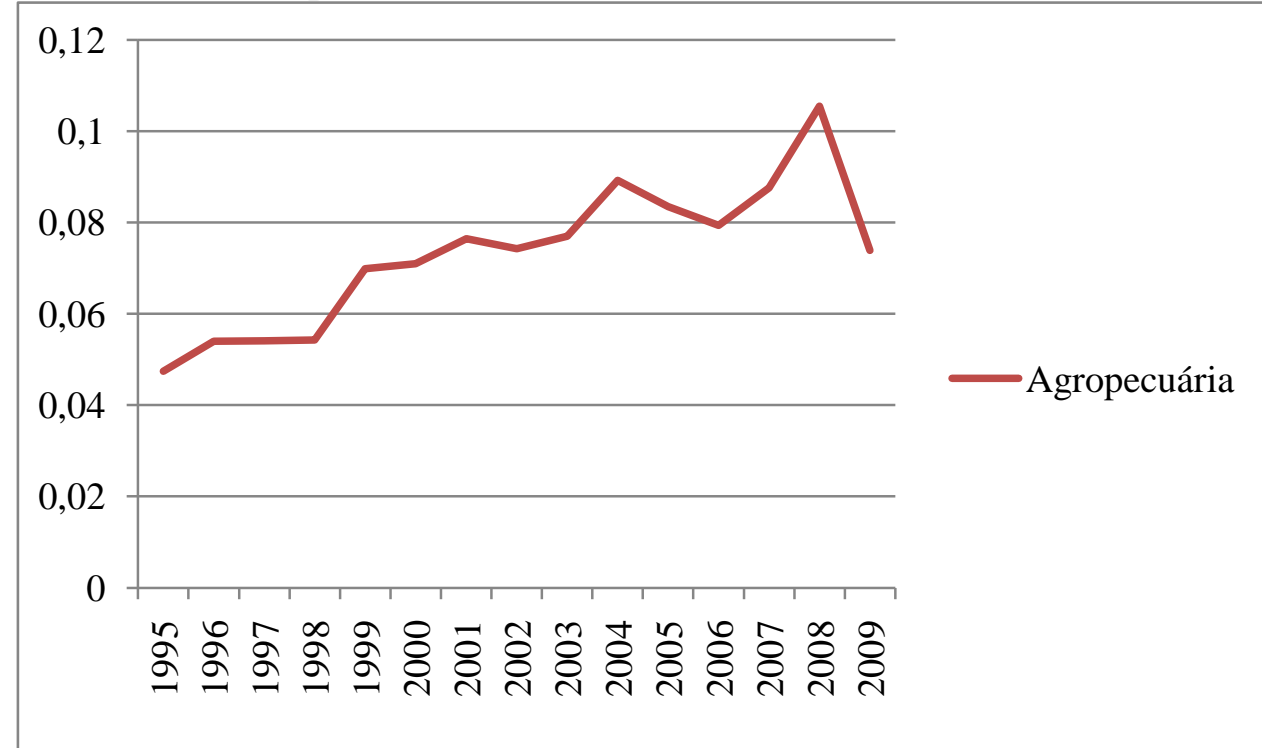

Fonte: Elaboração própria a partir das MIPs estimadas pelo NEREUS com base no SCN (IBGE, 2009).

O Gráfico5 mostra os valores que expressam dependência de insumos importados do setor agropecuário durante o período analisado. Por ele é possível observar que, embora este setor não apresente dependência externa para realizar suas atividades produtivas os valores tem se elevado no decorrer dos anos (com exceção do ano pós-crise 2008). No ano de 1995, o setor agropecuário demandava direta e indiretamente para cada real produzido cerca de $\mathrm{R} \$ 0,04$ de insumos importados sendo que este valor mais que duplica em 2008 chegando a $\mathrm{R} \$ 0,10$. 
Quando analisado o vetor coluna de requerimentos diretos e indiretos por insumos importados deste setor vê-se que os principais insumos demandados no ano de 2008 são: elementos químicos; refino de petróleo; químicos diversos; e petróleo e gás.

Ao contrário do que mostra o Gráfico anterior, o Gráfico6, em que estão representados os valores que expressam dependência da economia por insumos importados do setor de agropecuária, demonstra uma queda em tais índices a partir de 2003. Desta forma pode-se observar que ainda que a economia demonstre requerimentos de importação de insumos deste setor, esta tem perdido força nos últimos anos de análise.

Constata-se através do Gráfico6 que, em 1995, a economia importava direta e indiretamente insumos agropecuários para cada real produzido pelos demais setores o valor de $\mathrm{R} \$ 0,16$ chegando a $\mathrm{R} \$ 0,19$ em 2002 , porém em 2009 este valor se reduz para $\mathrm{R} \$ 0,10$. Desta forma o grau de dependência externa por insumos deste setor tem se demonstrado decrescente ao longo do período estudado. Ao analisar o vetor linha de requerimentos diretos e indiretos da economia por importação do setor agropecuário observa-se que os setores que apresentam maior dependência deste insumo são: $1^{\circ}$ produtos alimentares; $2^{\circ}$ fabricação de óleos vegetais; $3^{\circ}$ beneficiamento de produtos vegetais; $4^{\circ}$ agropecuária; e $5^{\circ}$ abate de animais.

Gráfico 6 - Valor do Requerimento Direto e Indireto da Economia por Insumos Importados do Setor de Agropecuáriade 1995 a 2009 (em reais)

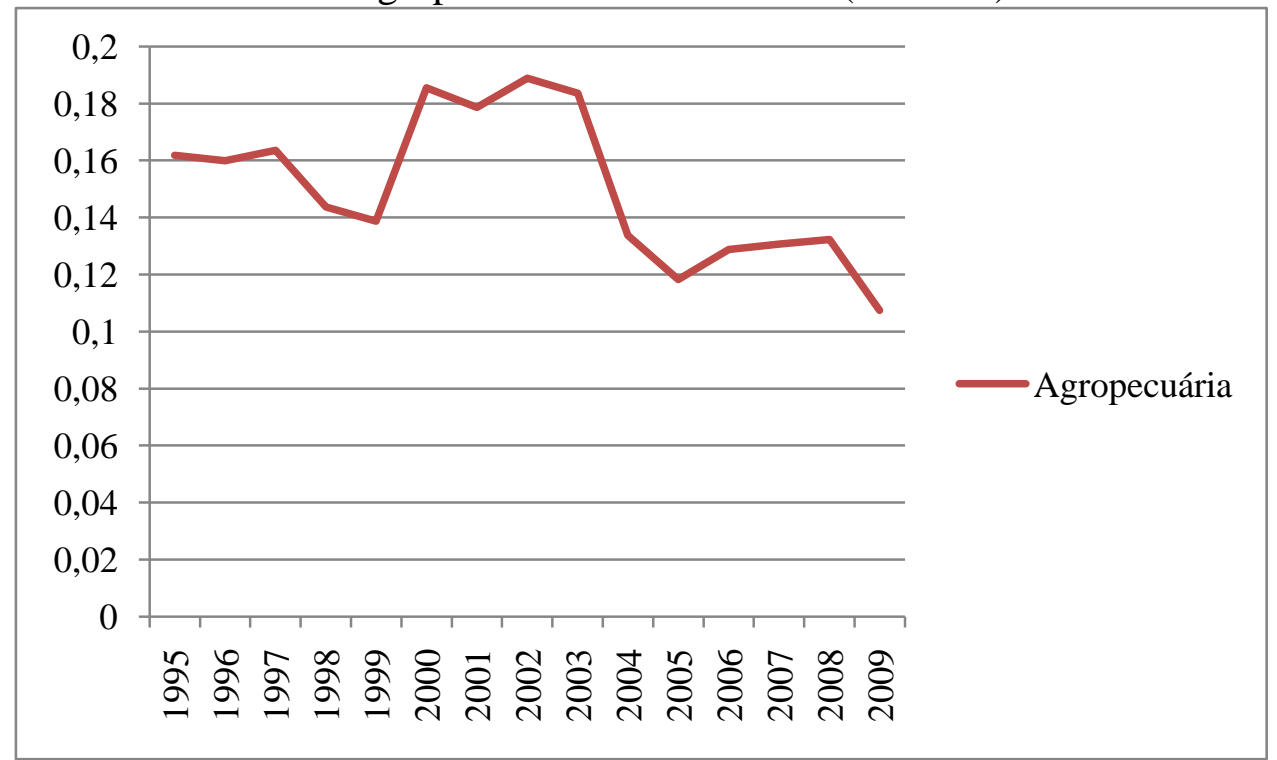

Fonte: Elaboração própria a partir das MIPs estimadas pelo NEREUS com base no SCN (IBGE, 2009).

Desta forma, vê-se que, embora o Brasil tenha destaque no cenário internacional historicamente devido ao seu desempenho econômico no setor agropecuário, a economia brasileira para produzir apresenta dependência externa relacionada a este setor. No entanto, é possível observar que por um lado esta dependência tem se mostrado em queda, enquanto por outro lado a dependência do setor por insumos importados tem indicado tendência ascendente nos últimos anos de análise. 


\section{CONCLUSÃO}

A indústria intensiva em recursos naturais possui juntamente ao setor agropecuário grande relevância para a economia brasileira. Este último tem historicamente impulsionado as exportações sendo, portanto, importante gerador de renda. Existe uma discussão na literatura em que se argumenta que a indústria brasileira tem passado por um processo de reestruturação, no qual a indústria intensiva em recursos naturais tem gradativamente ganhado importância no setor industrial.

O presente estudo possibilitou a análise de setores de importância econômica para o país que possuem dependência externa de insumos. Também foram analisados os setores em que, quando há expansão da produção doméstica, a demanda de importação dos insumos por ele produzidos se eleva mais que a média da economia. Outra questão verificada diz respeito à capacidade de encadeamento dos setores que pertencem à indústria intensiva em recursos naturais e do setor agropecuário, dados seus respectivos índices de ligação.

Conclui-se que, embora a agropecuária seja um setor de destaque na economia brasileira, sua produção, seja devido quantidade ou conteúdo produzido, não tem sido capaz de suprir a demanda interna, de modo que a economia apresentou no período estudado dependência de insumos importados relacionados a este setor. Sendo importante destacar que o setor foi classificado como dependente da demanda intersetorial, ou seja, um fornecedor importante, produzindo encadeamentos à jusante da cadeia produtiva. Pode-se inferir, desta forma, que parte dos transbordamentos gerados pelo setor de agropecuária se transfere para o exterior, dado a compra de insumos de fornecedores externos pela economia, sendo em média do período estudado o valor do requerimento direto e indireto por importação da economia relacionado a este setor igual $\mathrm{R} \$ 0,15$ para cada real produzido.

Foi constatado que o setor de refino de petróleo foi o que desempenhou papel de destaque nos anos de análise. Considerado um setor chave foi classificado como T. II, no que diz respeito ao seu grau de dependência externa, mostrando a grande fragilidade da economia em relação a este setor. Esta consideração deve-se ao fato de que, não só o setor para produzir foi considerado demandante de insumos importados, como a economia apresentou uma média de $\mathrm{R} \$ 0,93$ de demanda de importação de insumos desse setor para cada real produzido pelos demais setores no período analisado. Assim, a produção deste setor deve ser intensamente incentivada, já que no período esta se mostrou aquém de atender a demanda interna. Da mesma forma, os setores fornecedores de insumo para o setor de refino de petróleo deveriam ser estimulados internamente, de modo a permitir que os espraiamentos advindos do setor sejam absorvidos domesticamente.

Por fim, conclui-se que a indústria intensiva em recursos naturais, que vem se destacando economicamente nos últimos anos, possui divergência quanto ao seu grau de dependência externa. Isto porque os setores ligados à produção de alimentos foram, com exceção do setor de beneficiamento de produtos vegetais, classificados como T. IV, ou seja, apresentam requerimentos diretos e indiretos por insumos importados abaixo da média, de forma que se fomentados, o volume de importação não sofreria grandes variações. No entanto, os setores ligados à indústria extrativa mineral exibiram um resultado contrário, ou seja, são setores que se estimulados acresceria a dependência externa do país. 
Assim, a economia brasileira tem concentrados seus esforços na produção de setores que intensificam a dependência externa do país. Em consequência de suas atividades envolverem operações de compra de insumo de fornecedores estrangeiros, o poder de encadeamento destes setores se desvanece, perdendo a capacidade de geração direta e indireta de renda e emprego ao diminuir o conteúdo doméstico em sua produção. Portanto, embora os setores aqui discutidos tenham colaborado para o crescimento econômico do país, também o tem feito no sentido de aprofundar a dependência com o setor externo.

\section{REFERÊNCIAS BIBLIOGRÁFICAS}

BRUNO, M.; ARAÚJO, E.; PIMENTEL, D. Regime cambial e mudança estrutural na indústria de transformação brasileira: novas evidências para o período (1994-2008). ENCONTRO NACIONAL DA ANPEC, v. 37, 2009.

ERBER, F. S. O Padrão de Desenvolvimento Industrial e Tecnológico e o Futuro da Indústria Brasileira. Revista de Economia Contemporânea, v.5, p. 169-206, 2001.

DE ARAUJO, E. C.; LEITE, M. V. C. Sobreapreciação cambial no Brasil: estimativa, causas e consequências (1994-2008). Texto para Discussão, Instituto de Pesquisa Econômica Aplicada (IPEA), 2009.

GUILHOTO. J. J.M. Análise de insumo e Produto: Teoria e Fundamentos Apostila de conceitos básicos de Insumo e Produto. Universidade de São Paulo - USP. 2004.

Guilhoto, J.J.M., U.A. Sesso Filho. Estimação da Matriz Insumo-Produto Utilizando Dados Preliminares das Contas Nacionais: Aplicação e Análise de Indicadores Econômicos para o Brasil em 2005. Economia \& Tecnologia. UFPR/TECPAR. Ano 6, Vol 23, Out./Dez. 2010.

Guilhoto, J.J.M. e U. Sesso Filho. Estimação da Matriz Insumo-Produto a Partir de Dados Preliminares das Contas Nacionais. Economia Aplicada. Vol. 9. N. 2. Abril-Junho. pp. 277299. 2005.

Instituto Brasileiro de Geografia e Estatística - IBGE. Sistemas de contas nacionais: Brasil, 2005-2009. Contas Nacionais número 34. Rio de Janeiro: IBGE; 2011.

KUME, H.; PIANI, G.; SOUZA, C. F. A política brasileira de importação no período 198798: descrição e avaliação. Rio de Janeiro: IPEA, 2000.

MORCEIRO, P; GOMES, R; MAGACHO, G. R. Conteúdo Importado na Produção Industrial e na Demanda Final do Brasil Recente: uma proposta de indicadores de importação e de conteúdo nacional/estrangeiro. In: $40^{\circ}$ ENCONTRO NACIONAL DE ECONOMIA DA ANPEC. Pernambuco, jul. 2012.

MILLER, R.E; BLAIR, P.D. Input-output analysis: foundations and extensions. Englewood Cliffs, New Jersey: Prentice-Hall, Inc., 2009. 464p.

NASSIF, André. Há evidências de desindustrialização no Brasil?. Revista de economia política, v. 28, n. 1, p. 72-96, 2008.

ORGANIZATION FOR ECONOMIC COOPERATION AND DEVELOPMENT.OECD. Science, technology and industry scoreboard 2005.Paris: Organization for Economic 
Cooperation and Development, 2005. 210 p. Disponível em

$:<$ http://www.sourceoecd.org/scienceIT/9264010556>. Acesso em: 02/01/2015.

OREIRO, José Luis; FEIJÓ, Carmem A. Desindustrialização: conceituação, causas, efeitos e o caso brasileiro. Revista de economiapolítica, v. 30, n. 2, p. 219-232, 2010.

PAVITT, K. Sectoral patterns of technical change: towards a taxonomy and a theory. ResearchPolicy, Vol. 13, N.6, p. 343-373, 1984.

SCHUSCHNY, A. R. Tópicos sobre el modelo de insumo-producto: teoría y aplicaciones. Santiago de Chile: CAPAL, 2005. (Serie Estudios Estadísticos y Prospectivos, 37). 
Apêndice 1 - Valores dos Índices de Ligação para frente e para trás de 1995 a 2009

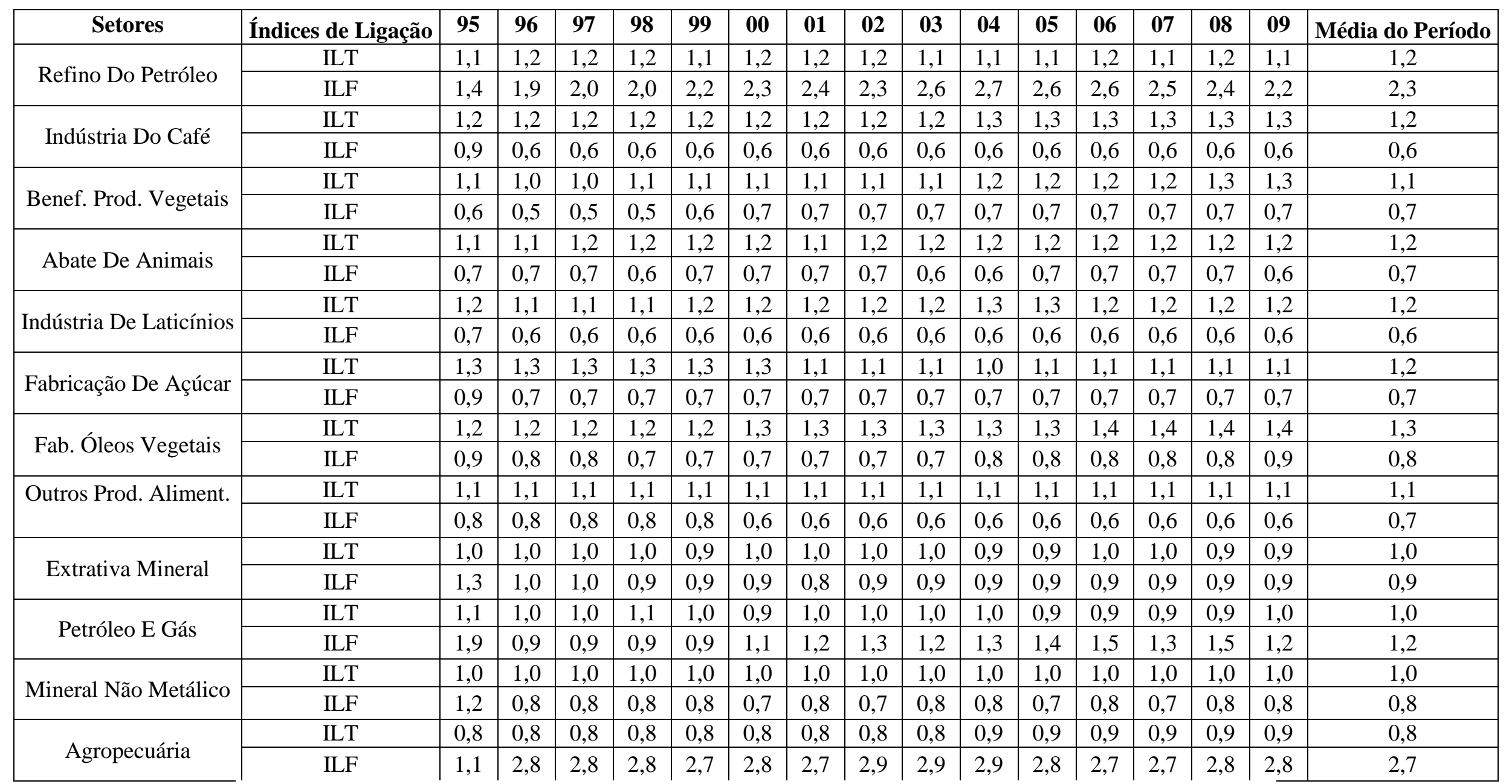

Fonte: Elaboração própria a partir das MIPs estimadas pelo NEREUS com base no SCN (IBGE, 2009). 